\title{
Health, Wellbeing and Self-Esteem: Web-Based Support in Children with Urogenital or Bowel Malformation
}

\author{
Agneta Simeonsdotter Svensson ${ }^{1,2}$, Margaretha Jenholt Nolbris ${ }^{2,3,4}$, Gundela Holmdahl5, \\ Anna-Lena Hellström ${ }^{2,4,5^{*}}$ \\ ${ }^{1}$ Department of Education, Communication and Learning, University of Gothenburg, Gothenburg, Sweden \\ ${ }^{2}$ Centre for Person-Centred Care (GPCC), University of Gothenburg, Gothenburg, Sweden \\ ${ }^{3}$ Centre for Children's Right to Health, Queen Silvia Children's Hospital, Gothenburg, Sweden \\ ${ }^{4}$ The Institute of Health and Care Sciences, Sahlgrenska Academy, University of Gothenburg, Gothenburg, \\ Sweden \\ ${ }^{5}$ Institute of Women and Children's Health, University of Gothenburg, Pediatric Urology Section, Queen Silvia \\ Children's Hospital, Gothenburg, Sweden \\ Email: agneta.simeonsdotter@ped.gu.se,margaretha.nolbris@fhs.gu.se,gundela.holmdahl@vgregion.se, \\ *annalena.hellstrom@fhs.gu.se
}

Received 17 February 2016; accepted 12 March 2016; published 15 March 2016

Copyright (C) 2016 by authors and Scientific Research Publishing Inc.

This work is licensed under the Creative Commons Attribution-NonCommercial International License (CC BY-NC). http://creativecommons.org/licenses/by-nc/4.0/ (c) (i) () Open Access

\begin{abstract}
Background: Children with urogenital malformation or bowel disturbances are a vulnerable group and are at risk of experiencing ill health. At school they have to face and cope with situations they are unused to and often feel excluded. There is a lack of studies investigating prevention of ill health in this group of children. Objective: The aim of the study was to investigate the health/wellbeing and self-esteem, before and after a one-year intervention comprising person-centred, webbased learning support, in preschool children born with malformations in the urethra, bladder, genitals and/or bowel. Study design: Nine boys and one girl participated, aged 3 - 7 years (study group) with diagnoses of epispadia, bladder exstrophy, urethra valves and Hirschprung's disease. Two questionnaires were used, developed to measure index of health/wellbeing and self-esteem in younger children. In the study group, the interviews were repeated after one year. The group was compared with a control group of 20 healthy, age-matched children. Results: Before the intervention, there were no differences in wellbeing (Children condition index) between the study group and the control group. One year after the start of the web-based preschool, wellbeing in the study group had slightly improved, but not significantly compared to before the intervention. No
\end{abstract}

${ }^{*}$ Corresponding author.

How to cite this paper: Svensson, A.S., Nolbris, M.J., Holmdahl, G. and Hellström, A.-L. (2016) Health, Wellbeing and Self-Esteem: Web-Based Support in Children with Urogenital or Bowel Malformation. Open Journal of Pediatrics, 6, 82-90. http://dx.doi.org/10.4236/ojped.2016.61014 
significant difference was found compared to the control group. When measured self-esteem (I think I am) before the intervention, the study group had significantly better self-esteem compared to the control group. One year later, there was a slight improvement in self-esteem, but two children scored worse in the domain Psychological wellbeing. In comparison with the group of healthy children, the self-esteem in the study group was better for total sum $(p=0.0002)$. Discussion: Wellbeing and self-esteem seem to be good in children aged 3 - 7 years with uro-genital and bowel malformations, according to the findings of this study. This is better than reports concerning older children. Despite high initial values compared to healthy children, continued, but not significant, improvement in wellbeing and self-esteem was shown one year after intervention. Conclusions: The results of the intervention aimed at promoting health, wellbeing and self-esteem are promising but a longer-term follow-up in a larger group of children is needed.

\section{Keywords}

Bladder, Person-Centred Care, Preschool Children, Self-Esteem, Urogenital Malformation, Web-Based Intervention, Wellbeing

\section{Introduction}

Long-term illness is usually a challenge for both children and their families [1]. Children with urogenital malformation or bowel disturbances are a vulnerable group who are at greater risk of experiencing ill health. They are often supported in situations related to their malformation by parents and others. When at school, the child suddenly has to face and cope with situations they are not used to; they often feel excluded, afraid of relationships with the opposite sex and subjected to bullying [2]-[4]. They express a great need for support in daily life [5]-[8]. The social and emotional consequences of long-term illness need to be addressed [9]. However, there is lack of studies investigating prevention of ill health in this group of children.

Health promotion is the process of enabling people to increase their control over, and to improve their health. To reach a state of complete physical, mental and social wellbeing, the child must be able to identify and to realize aspirations, to satisfy needs, and to change or cope with the environment. Health is, therefore, seen as a resource, not the objective, in everyday life. Health is a positive concept that emphasizes social and personal resources, as well as physical capacities. Health promotion is not just the responsibility of the health sector; it goes beyond healthy lifestyles to wellbeing [10]. However, the needs of children with the same disease are not necessarily the same. Person-centred care (PCC) is explained as focusing on the person and not on the illness. The purpose is to make care and treatment more personal and to understand behaviour and symptoms from the perspective of the individual patient. To do this, it is important to proceed from knowledge of the sick person's living patterns and priorities [11]. Studies have been conducted with positive outcomes, mainly for adults with long-term illness but also for young people [12]-[15].

The present study is part of a larger project studying health and wellbeing using person-centred, web-based learning in children with severe urogenital, urological and bowel malformations [16] [17]. Findings from the studies in this project are qualitative in design and show the development of the intervention. The use of SKYPE for interviewing children was also evaluated. This method can be used in the child's home and is convenient for both the child and the family. The ability to use the body language also facilitated the understanding of the conversation, particularly in the youngest children. The intervention could identify wellbeing, resources, needs, and wishes. The children were interested and able to discuss relations, emotions and their own body. That learning had taken place was shown by realizing something new, reflecting on it, and then using the knowledge in a new context in their daily lives.

The aim of the study was to investigate the effect on health/wellbeing and self-esteem, before and after oneyear intervention in children aged $3-7$ years born with malformations in the urethra, bladder, genitals and/or bowel. The results of the intervention, person-centred, web-based learning support, are compared with the findings in a control group of healthy children. 


\section{Material and Methods}

\subsection{Instruments}

Two questionnaires were used, developed to measure health/wellbeing and self-esteem in younger children. The first instrument (health and wellbeing) was adopted from the "Children condition index" which has 36 questions with four possible responses supported by a face scales from very sad to very happy [18]. The second instrument (self-esteem) was adopted from "I think I am" and has 32 questions with yes or no response alternatives [19].

The questions were read to the children, and explained if necessary, the interviewer filled in the questionnaire. In the study group of children with malformations the interviews were repeated after one year. The same interview technique was used in the group of healthy, age-matched controls.

\subsection{Intervention}

The intervention was offered using the web and SKYPE; the child received a tablet and the necessary equipment. The programme was based on a story about two pre-school children, Sara and Max. There were instructions (a voice-over), sounds and images illustrating various actions carried out by Sara and Max

(http://www.webbförskolan.se). The design aimed to strengthen the health, and personal resources of the child and cater to the child's joy in playing. Each child had a personal web-teacher (two of the authors) and the communication, once a month, was tape-recorded. The children were encouraged to use the programme whenever they wished between the follow-ups.

The stories and images were used as a foundation for the conversation between the web-teacher and the child. The children were encouraged to tell their story but the parents' support was welcomed if they thought it was needed.

To give the child access to the vocabulary and the opportunity to learn to understand feelings, there was a special section that dealt with relationships such as in the family, at preschool, school and with friends. Social rules were discussed as well as the right to integrity. Another section was about the functioning of the body, which focused on the child's health. There was also a section that dealt with the child's specific malformation, narrated in the third person.

\subsection{Participants}

The participants comprised nine boys and one girl, aged 3 - 7 years (study group); their diagnoses were: epispadia, bladder exstrophy, posterior urethra valves with renal insufficiency and Hirschprung's disease. The control group was made up of 20 healthy, age-matched children. All children with severe malformation in the urethra, genitals and bowel who were treated at the hospital, were invited to join the intervention over a period of 18 months. None of the families declined participation. The healthy children were recruited from preschool settings.

\subsection{Statistical Analysis}

The distribution of continuous variables is given as the mean, SD, median, minimum and maximum. To compare change over time, the Wilcoxon Signed Rank test was used for continuous variables. For comparison between the study group and controls the Mann-Whitney U-test was used for continuous variables. All significance tests were two tailed and conducted at the 5\% significance level.

SAS System version 9, SAS Institute, Cary, NC, USA was used for all analyses.

\section{Results}

\subsection{Children Condition Index}

Before intervention, there were no differences in wellbeing, measured using the "Children condition index", between the study group of children with uro-genital and bowel malformations and the control group of healthy children of the same age (Table 1). In the relations domain it was found that the children in the study group could choose friends to play with and were teased to the same extent as healthy children.

One year after the start of the web-based preschool, wellbeing in the study group was slightly, but not signify- 
Table 1. Children condition index: children with urogenital and bowel malformations before and one year after intervention, changes and comparison with a control group of healthy children.

\begin{tabular}{|c|c|c|c|c|c|c|c|c|}
\hline \multirow[b]{3}{*}{ Domain } & \multicolumn{4}{|c|}{ Study group } & \multicolumn{4}{|c|}{ Controls } \\
\hline & \multirow[b]{2}{*}{ Before $(n=10)$} & \multirow[b]{2}{*}{ After $(n=10)$} & \multicolumn{2}{|c|}{$\begin{array}{l}\text { Change from } \\
\text { before to after }\end{array}$} & \multicolumn{2}{|c|}{$\begin{array}{l}\text { Age-matched group (1) } \\
\text { before intervention }\end{array}$} & \multicolumn{2}{|c|}{$\begin{array}{l}\text { Age-matched group (2) } \\
\text { after intervention }\end{array}$} \\
\hline & & & & p-value & Before $(n=20)$ & p-value & After $(n=20)$ & p-value \\
\hline $\begin{array}{l}\text { Health/ } \\
\text { comfort }\end{array}$ & $\begin{array}{c}75.6(14.1) \\
77.8(48.1 ; 92.6)\end{array}$ & $\begin{array}{c}83.0(9.4) \\
83.3(66.7 ; 96.3)\end{array}$ & $\begin{array}{c}7.41(18.06) \\
11.11(-25.9 ; 33.3)\end{array}$ & 0.18 & $\begin{array}{c}74.1(8.7) \\
70.9(61.9 ; 92.6)\end{array}$ & 0.55 & $\begin{array}{c}81.8(11.2) \\
81.5(66.7 ; 100.0)\end{array}$ & 0.71 \\
\hline Environment & $\begin{array}{c}68.8(12.5) \\
66.7(44.4 ; 83.3)\end{array}$ & $\begin{array}{c}60.4(6.1) \\
61.1(50.0 ; 72.2)\end{array}$ & $\begin{array}{c}-8.33(9.98) \\
-5.56(-23.3 ; 5.6)\end{array}$ & 0.039 & $\begin{array}{c}66.4(10.5) \\
66.7(44.4 ; 83.3)\end{array}$ & 0.64 & $\begin{array}{c}63.9(11.2) \\
61.1(38.9 ; 83.3)\end{array}$ & 0.22 \\
\hline Play & $\begin{array}{c}79.4(18.5) \\
80.6(50.0 ; 100.0)\end{array}$ & $\begin{array}{c}84.2(10.0) \\
83.3(66.7 ; 100.0)\end{array}$ & $\begin{array}{c}4.72(19.16) \\
4.17(-16.7 ; 41.7)\end{array}$ & 0.66 & $\begin{array}{c}80.0(13.7) \\
83.3(58.3 ; 100.0)\end{array}$ & 0.97 & $\begin{array}{c}86.8(10.9) \\
87.5(66.7 ; 100.0)\end{array}$ & 0.56 \\
\hline Relations & $\begin{array}{c}75.2(11.8) \\
75.9(55.6 ; 90.5)\end{array}$ & $\begin{array}{c}75.5(9.6) \\
75.6(59.3 ; 85.2)\end{array}$ & $\begin{array}{c}0.32(15.6) \\
1.85(-24.1 ; 26.0)\end{array}$ & 0.98 & $\begin{array}{c}72.8(6.9) \\
70.4(63.0 ; 87.5)\end{array}$ & 0.56 & $\begin{array}{c}74.1(11.4) \\
72.2(55.6 ; 100.0)\end{array}$ & 0.53 \\
\hline $\begin{array}{l}\text { Participation } \\
\text { in decisions }\end{array}$ & $\begin{array}{c}54.8(12.7) \\
57.1(38.1 ; 76.2)\end{array}$ & $\begin{array}{c}64.3(14.6) \\
69.0(38.1 ; 81.0)\end{array}$ & $\begin{array}{c}9.52(13.65) \\
4.76(-4.76 ; 33.33)\end{array}$ & 0.078 & $\begin{array}{c}56.5(10.4) \\
57.1(38.9 ; 76.2)\end{array}$ & 0.69 & $\begin{array}{c}61.2(11.7) \\
57.1(42.9 ; 85.7)\end{array}$ & 0.62 \\
\hline
\end{tabular}

For continuous variables Mean (SD)/Median (Min; Max) $/ \mathrm{n}=$ is presented.

For comparison within study group over time the Wilcoxon Signed Rank test was used.

For comparison between groups the Mann-Whitney U-test was used.

cantly improved in most domains. In the relation domain, the children were still as happy as before with their friends and teachers at school.

In the environment domain, however, there was a negative change with the study group now being less satisfied with the question about the "traffic in the surrounding" and more often hurting themselves in school ( $\mathrm{p}=$ 0.039).

No significant difference was found in comparison to healthy children of the same age.

\subsection{Think I Am}

Before the intervention the study group had significantly better self-esteem in two of the five domains compared to the control group of healthy children of the same age, measured using "I think I am" (Table 2). The better values were found in the domains Psychological wellbeing $(p=0.033)$ and relation to parents $(p=0.046)$.

One year after the start of the intervention, there was a slight improvement in self-esteem compared to before, but in the Psychological wellbeing domain two children had also got worse. However, a non-significant trend could be seen despite good values from before; particularly in the Physical characteristics ( $p=0.063)$ domain all the children in the study group were now happy with their appearance and name. The mean improvement in total sum of all domains was 6.51 (SD 9.20, $\mathrm{p}=0.059$ ).

In comparison with the group of healthy children, the self-esteem in the study group was better for total sum $(p=0.0002)$. Surprisingly in the Relations to others domain, we found that children in the control group could have feelings of loneliness. This was not found in the study group of children with malformations $(p=0.0023)$. In the Psychological wellbeing and Relation to parents domains we also found better values for the study group, $\mathrm{p}=0.0092$ and $\mathrm{p}=0.0055$ respectively.

\section{Discussion}

Findings from the Children condition index questionnaire show that, before intervention, wellbeing was in general the same in preschool children with uro-genital and bowel malformations and healthy children. Self-esteem (I think I am questionnaire) was significantly better in the study group in two out of five domains. This supports the suggestion that attention given to preschool children with serious diseases by parents and others may strengthen their wellbeing.

One year after intervention, wellbeing and self-esteem were slightly improved compared to before and to healthy children. The children were satisfied with relations with their parents, friends and teachers at school.

The goal of the intervention, Web-based person-centred learning support, was to prevent ill health during school years. The children who participated were aged 3 - 7 years and results equal to those for healthy children 
Table 2. I think I am: children with urogenital and bowel malformations before and one year after intervention, changes and comparison with a control group of healthy children.

\begin{tabular}{|c|c|c|c|c|c|c|c|c|}
\hline \multirow[b]{3}{*}{ Domain } & \multicolumn{4}{|c|}{ Study group } & \multicolumn{4}{|c|}{ Controls } \\
\hline & \multirow[b]{2}{*}{ Before $(n=10)$} & \multirow[b]{2}{*}{ After $(n=10)$} & \multicolumn{2}{|c|}{$\begin{array}{l}\text { Changes from } \\
\text { before to after }\end{array}$} & \multicolumn{2}{|c|}{$\begin{array}{l}\text { Age-matched group (1) } \\
\text { before intervention }\end{array}$} & \multicolumn{2}{|c|}{$\begin{array}{l}\text { Age-matched group (2) } \\
\text { after invention }\end{array}$} \\
\hline & & & & p-value & Before $(n=20)$ & p-value & $\operatorname{After}(n=20)$ & p-value \\
\hline $\begin{array}{c}\text { Physical } \\
\text { characteristics }\end{array}$ & $\begin{array}{l}3.52(2.53) \\
4.0(0 ; 6)\end{array}$ & $\begin{array}{l}5.80(0.63) \\
6.0(4 ; 6)\end{array}$ & $\begin{array}{l}2.28(2.81) \\
2.0(-2 ; 6)\end{array}$ & 0.063 & $\begin{array}{l}4.33(1.44) \\
4.0(2 ; 6)\end{array}$ & 0.56 & $\begin{array}{l}4.83(1.59) \\
6(2 ; 6)\end{array}$ & 0.100 \\
\hline Skills & $\begin{array}{l}3.60(2.27) \\
4.0(0 ; 6)\end{array}$ & $\begin{array}{l}4.20(1.99) \\
4.0(0 ; 6)\end{array}$ & $\begin{array}{c}0.600(2.989) \\
2.0(-6 ; 4)\end{array}$ & 0.46 & $\begin{array}{l}1.87(1.82) \\
2.0(-1 ; 4)\end{array}$ & 0.053 & $\begin{array}{c}3.33(2.61) \\
4(-2 ; 6)\end{array}$ & 0.47 \\
\hline $\begin{array}{l}\text { Psychological } \\
\text { wellbeing }\end{array}$ & $\begin{array}{l}5.60(2.27) \\
6.0(0 ; 8)\end{array}$ & $\begin{array}{l}7.20(1.03) \\
8.0(6 ; 8)\end{array}$ & $\begin{array}{l}1.60(2.80) \\
1.0(-2 ; 8)\end{array}$ & 0.16 & $\begin{array}{l}3.67(2.06) \\
4.0(0 ; 6)\end{array}$ & 0.033 & $\begin{array}{l}4.83(2.17) \\
5.0(2 ; 8)\end{array}$ & 0.0092 \\
\hline $\begin{array}{l}\text { Relation to } \\
\text { parents }\end{array}$ & $\begin{array}{l}3.80(2.39) \\
4.0(0 ; 6)\end{array}$ & $\begin{array}{l}4.60(1.35) \\
4.0(2 ; 6)\end{array}$ & $\begin{array}{c}0.800(3.011) \\
1.0(-4 ; 6)\end{array}$ & 0.54 & $\begin{array}{l}1.50(2.43) \\
2.0(-2 ; 6)\end{array}$ & 0.046 & $\begin{array}{l}2.50(1.51) \\
2.0(0 ; 4)\end{array}$ & 0.0055 \\
\hline $\begin{array}{l}\text { Relations to } \\
\text { others }\end{array}$ & $\begin{array}{l}4.80(2.70) \\
6.0(-2 ; 6)\end{array}$ & $\begin{array}{l}6.00(0.00) \\
6.0(6 ; 6)\end{array}$ & $\begin{array}{l}1.20(2.70) \\
0.0(0 ; 8)\end{array}$ & 0.50 & $\begin{array}{l}4.47(1.52) \\
4.0(2 ; 6)\end{array}$ & 0.22 & $\begin{array}{l}4.00(1.91) \\
4.0(0 ; 6)\end{array}$ & 0.0023 \\
\hline Total Sum & $\begin{array}{l}21.3(8.5) \\
23.7(4 ; 3)\end{array}$ & $\begin{array}{c}27.8(2.0) \\
28.0(24 ; 30)\end{array}$ & $\begin{array}{l}6.51(9.20) \\
6.1(-6 ; 24)\end{array}$ & 0.059 & $\begin{array}{c}15.7(6.1) \\
14.2(4.3 ; 28)\end{array}$ & 0.098 & $\begin{array}{c}19.5(4.3) \\
20.0(12 ; 26)\end{array}$ & 0.0002 \\
\hline
\end{tabular}

For continuous variables Mean (SD)/Median (Min; Max)/n= is presented.

For comparison within study group over time the Wilcoxon Signed Rank test was used.

For comparison between groups the Mann-Whitney U-test was used.

should be sufficient.

However, a one-year follow-up is too short to show the intervention's effectiveness in the school years as only a few had started school at that time. Nevertheless the findings are important in that the intervention seemed to affect health and wellbeing positively. The low number of participants in this one-centre evaluation was a limitation. Preschool children with severe malformations are fortunately rare and to be able to show significant differences in a small number requires a clear difference in all the children. A limitation could be that the questionnaires used are validated for older children, four and six years of age, and in the present study some younger children participated. In order to over bridge this problem each child was individually interviewed and the questions could thus be explained and discussed to ensure understanding. A multi-centre study with a longer follow-up needs to be performed as a next step.

The children condition index questionnaire is aimed at measuring health and wellbeing in healthy preschool and school children. The Karlskoga-Degerfors report in 4 - 5-year-old healthy children found that ten percent did not feel well. According to this report, play at school and at home usually predicts health and wellbeing [18]. The children with uro-genital and bowel malformations were largely satisfied with their play (mean 79.4 before an 84.2 after intervention). Values were improved in all domains (NS) except environment; they were less satisfied with the traffic and that they often hurt themselves when in school.

A report of a study in 8 - 9-year-old healthy Swedish children using the same questionnaire (Children Condition Index), shows that their own body followed by family relations had the greatest impact on total satisfaction with life and living conditions. In comparison with children from Peru, Sri Lanka and Vietnam they had better values on average [20]. Further, they had a better index in a comparison with disabled children in general [20]. It is interesting that in the present study that, our group of preschool children with uro-genital and bowel malformations presented results that were quite similar to those of the control group of healthy children.

The "I think I am" questionnaire measures self-esteem and has been used before in studies of self-esteem in children with urinary tract and bowel disturbances [8] [21]. The version adapted for use with younger children in the first grades in school was used. Most of the children in the present study were younger but had no problems answering when the questions were read to them. Children and adolescents with cystic fibrosis and healthy controls along with their parents participated in another study, which looked at quality of life using the PedsQL $^{\text {TM }} 4.0$ SF15 questionnaire. In the 2 - 4 years QoL showed no significant difference whereas in the 5 - 7 age group there was a significant difference in the physical and general subgroups, but not in other aspects, compared to healthy controls.

According to the findings from our study it seems that younger children, despite serious illness, experience 
wellbeing and self-esteem. This usually changes when they start school [22]. Health promotion, as in the intervention evaluated, was person-centred in that the child's story was listened to and the child's specific needs, viewed from the child's perspective, were met. Supporting their communication skills and learning enabled them to increase their control in daily life [10] [11]. We do not know if these efforts will contribute to maintaining wellbeing and self-esteem later on in school. But, from a short-term perspective it is a promising beginning in view of there not being anything else to offer.

\section{Conclusion}

Wellbeing and self-esteem seem to be good in preschool children with uro-genital and bowel malformations according to our findings. One year after intervention, despite having high values before, a slight, but not significant improvement in wellbeing and self-esteem was shown. The group who received the intervention, person-centred, web-based learning support, was compared to a control group of healthy children.

\section{Acknowledgements}

This research is part of the work carried out at the Centre for Person-Centred Care at the University of Gothenburg (GPCC), Sweden. We would like to thank all the children and their parents who participated in the study and shared their experiences. We would also like to thank Gunilla Wärnström for her excellent work with the illustrations and Richard Ingemannsen for valuable technical support. Finally, we would like to thank Alicia Garcia for the work with organizing data. We thank Nils-Gunnar Pehrsson for excellent help with the statistical analyses.

\section{Conflict of Interest}

None.

\section{Funding}

The study was financed by grants from the Swedish state under the agreement between the Swedish government and the county councils concerning economic support for research and the education of doctors (ALF-agreement).

\section{References}

[1] Perrin, J.M., Shayn, M.W. and Bloom, S.R. (1993) Home and Community Care for Chronically Ill Children. Oxford University Press, New York.

[2] Wilson, C.J., Pistrang, N., Woodhouse, C.R. and Christie, D.J. (2007) The Psychosocial Impact of Bladder Exstrophy in Adolescence. Journal of Adolescent Health, 41, 504-508. http://dx.doi.org/10.1016/j.jadohealth.2007.05.021

[3] Ebert, A., Scheuering, S., Schott, G. and Roesch, W.H. (2005) Psychosocial and Psychosexual Development in Childhood and Adolescence within the Exstrophy-Epispadias Complex. The Journal of Urology, 174, 1094-1098. http://dx.doi.org/10.1097/01.ju.0000169171.97538.ed

[4] Pennison, M.C., Medrick, L., Grant, R., Price, D., Rosoklija, I. and Huang, L. (2013) A Survey to Assess Body and Self-Image in Individuals with Bladder Exstrophy: A Call for Psychosocial Support. The Journal of Urology, 190, 1572-1576. http://dx.doi.org/10.1016/j.juro.2013.02.028

[5] Hellström, A.L., Berg, M., Holmdahl, G. and Sillén, U. (2006) Feeling Good in Daily Life_From the Point of View of Boys with Urethral Valves. The Journal of Urology, 176, 1742-1746. http://dx.doi.org/10.1016/j.juro.2006.03.120

[6] Holmdahl, G., Sillén, U., Abrahamsson, K., Hellström, A., Kruse, S. and Sölsnes, E. (2007) Self-Catheterization during Adolescence. Scandinavian Journal of Urology and Nephrology, 41, 214-217. http://dx.doi.org/10.1080/00365590601017493

[7] Berntsson, L., Brydolf, M., Berg, M. and Hellström, A.-L. (2007) School Children and Adolescents’ Perception of Health, Well-Being and Participation. Scandinavian Journal of Caring Sciences, 21, 419-425. http://dx.doi.org/10.1111/j.1471-6712.2006.00490.x

[8] Hartman, J.W., Tang, J.E., Wilkinson, S.B., Tarnopolsky, M.A., Lawrence, R.L., Fullerton, A.V., et al. (2007) Consumption of Fat-Free Fluid Milk after Resistance Exercise Promotes Greater Lean Mass Accretion than Does Consumption of Soy or Carbohydrate in Young, Novice, Male Weightlifters. American Journal of Clinical Nutrition, 86, 373-381. 
[9] Reichenberg, K. and Broberg, A.B. (2000) Quality of Life in Childhood Asthma: Use of the Paediatric Asthma Quality of Life Questionnaire in a Swedish Sample of Children 7 to 9 Years Old. Acta Paediatrica, 89, 989-995. http://dx.doi.org/10.1111/j.1651-2227.2000.tb00423.x

[10] WHO (1986) Ottawa Charter for Health Promotion. http://www.who.int/healthpromotion/conferences

[11] Ekman, E., Swedberg, K.,Taft, C., Lindseth, A., Norberg, A., Brink, E., et al. (2011) Person-Centered Care-Ready for Prime Time. European Journal of Cardiovascular Nursing, 10, 248-251. http://dx.doi.org/10.1016/j.ejcnurse.2011.06.008

[12] Nordanstig, J., Charles, T., Hensäter, M., Perlander, A., Österberg, K. and Jivegård, L. (2014) Improved Quality of Life after 1 Year with an Invasive versus a Noninvasive Treatment Strategy in Claudicants One-Year Results of the Invasive Revascularization or not in Intermittent Claudication. Circulation, 130, 939-947. http://dx.doi.org/10.1161/CIRCULATIONAHA.114.009867

[13] Palstam, A., Larsson, A., Bjersing, J., Löfgren, M., Ernberg, M. and Bileviciute-Ljungar, et al. (2014) Perceived Exertion at Work in Women with Fibromyalgia: Explanatory Factors and Comparison with Healthy Women. Journal of Rehabilitation Medicine, 46, 773-780. http://dx.doi.org/10.2340/16501977-1843

[14] Borge, C.R., Mengshoel, A.M., Omenaas, E., Moum, T., Ekman, I., Lein, M.P., et al. (2015) Effects of Guided Deep Breathing on Breathlessness and the Breathing Pattern in Chronic Obstructive Pulmonary Disease: A Double-Blind Randomized Control Study. Patient Education and Counseling, 98, 182-190. http://dx.doi.org/10.1016/j.pec.2014.10.017

[15] Jenholt Nolbris, M. and Hedman Ahlström, B. (2014) Siblings of Children with Cancer-Their Experiences of Participating in a Person-Centered Support Intervention Combining Education, Learning and Reflection: Pre- and Post-Intervention Interviews. European Journal of Oncology Nursing, 3, 254-260. http://dx.doi.org/10.1016/j.ejon.2014.01.002

[16] Hellström, A.-L, Simeonsdotter Svensson, A., Pramling Samuelsson, P. and Jenholt Nolbris, M.A. (2012) Web-Based Programme for Person-Centred Learning and Support Designed for Preschool Children with Long-Term Illness: A Pilot Study of a New Intervention. Nursing Research and Practice, 2012, Article ID: 326506, 8 p. http://dx.doi.org/10.1155/2012/326506

[17] Simeonsdotter Svensson, A., Pramling Samuelsson, I., Hellström, A.-L. and Jenholt Nolbris, M. (2013) Experiences of SKYPE Communication in Education and Research-Data Collection Concerning Young Children with Long-Term Illness. Early Child Development and Care, 184, 1017-1030. http://dx.doi.org/10.1080/03004430.2013.841154

[18] Nöjt Barn Index (Children Condition Index). http://www.Karlskoga-Degeforskommuner2006-2008.Karlskoga.se

[19] Piers, E.V. and Harris, D.B. Children’s Self-Concept Scale ${ }^{\mathrm{TM}}$. Second Edition (Piers-Harris ${ }^{\mathrm{TM}} 2$ ). http://www.wpspublish.com/store/p/2912/

[20] The Children’s Ombudsman BR 2007:05. The Right to Be Heard. http://www.bo.se

[21] Hägglöf, B., Andrén, O., Bergström, E., Marklund, L. and Wendelius, M. (1998) Self-Esteem before and after Treatment in Children with Nocturnal Enuresis and Urinary Incontinence. European Urology, 33, 16-19. http://dx.doi.org/10.1159/000052236

[22] Kianifar, H.-R., Bakhshoodeh, B., Hebrani, P. and Behdani, F. (2013) Quality of Life in Cystic Fibrosis Children. Iranian Journal of Pediatrics, 23, 149-153. 


\section{Appendix}

Questions used for the study are adopted from questionnaires Nöjt barn index (Children condition index) and I think I am.

\section{Children condition index}

Reference: [18] Nöjt barn index (Children condition index)

http://www.Karlskoga-Degeforskommuner2006.2008.Karlskoga.se

The questionnaire includes 36 questions with four alternative responses supported by a face scale representing very sad to very happy.

\section{Domains}

\section{Health/comfort}

How are you right now? How was it to go to bed yesterday? Did you find it difficult to fall in sleep? How did you feel when you woke up? How did you feel earlier today? How did it feel to be left at preschool/school today? What was it like at preschool/school today? How do you feel? What was it like to answer these questions?

Environment

How do you like your room were you sleep? How do you like the food at home? If the family has pets; how do feel about that? If not; how do you feel about that? How do you like the food at preschool/school? Do you often get hurt at preschool/school? What do you think about that? Do you feel safe in the traffic? What do you think about that?

Play

How do you like your toys at home? How do you like playing at preschool/school? What are the toys like at preschool/school? How is playing outdoors at preschool/school?

\section{Relations}

Yesterday, what were the other children in the group like? What are the children usually like? What are the teachers like? If you have brothers and sisters, what are they like? If you don't have brothers or sisters, what is that like? Can you decide who you like to play with? Are you allowed to play with the ones you like to play with most at school/preschool? Are you ever teased at preschool/school? How did you feel last time you played alone? How did you feel last time you played at preschool/school?

\section{Participation in decisions}

Are you allowed to decide for yourself what to wear? What do you think about that? Can you decide for yourself what to eat at home? What do you think about that? May you decide what to play? What do you think about that? Can you decide yourself what TV you will watch and when? What do you think about that? Computer games? What do you think about that? Can you decide when to go to bed? What do you think about that? Do the teachers ask what you like to do at preschool/school? What do you think about that?

\section{I think I am}

Reference: [19] Piers, E.V. and Harris, D.B. Children’s Self-Concept Scale ${ }^{\mathrm{TM}}$, Second Edition (Piers-Harris ${ }^{\mathrm{TM}}$ 2): http://www.wpspublish.com/store/p/2912/

The questionnaire includes 32 questions with yes or no responses.

\section{Domains}

\section{Physical characteristics}

I have a nice face. For a girl: I would like to be a boy. For a boy: I would like to be a girl. I am tall enough. I am good in sports. I am quite ugly. My name is boring.

\section{Skills}

I am good at drawing. I am bad at math. I am doing well in school. Other children do better than I do. I am good at reading and writing. I am bad at singing.

Psychological Wellbeing

I am get angry easily. I am almost always happy. I am calm and steady. I often get moody and irritated. I feel happy. I often get sick. I am often sad. I like myself. 


\section{Relation to parents}

My parents are disappointed in me. I am quite equal to my parents. In my family, we make a lot of fuss. My parents trust me. My parents have too little time for me. In my family we often have fun together.

Relations to others

I often feel lonely. Other children are often nasty to me. I like my schoolmates. I feel like everybody else. I have many friends. My teacher is kind to me. 